\title{
Analysis Equity in Financing of Household's Health in Iran (By Concentration and Extended Concentration Index)
}

\author{
Ali Maher and Zahra Fazel
}

\begin{abstract}
Health status of societies is among the basic indices of economic and social development, and hence, investment in this section directly impacts on social welfare and economic growth. Low quality of health care and inequality in health care expenditure contributions can lead to different forms of social and economic consequences. This is the main concern of the public policymakers, in particular, those who are engaged with health care services. Hence, monitoring households' health expenditures, which can reflect socio-economic inequality, can provide valuable information for the health policymakers.

The concentration index and the extended concentration index introduced by Wgstaff (2002) is used to estimate inequality in health expenditures of urban households. Also, the household's expenditures in Iran are disaggregated into expenditure quintiles through selected years from 1989 (i.e., beginning of the development programs in Iran after the revolution) until 2014. To this end, Iran's annual household's survey data produced by Iran statistic center is used.

The concentration index has an upward trend from 1989 to 2005, and after that, it has a fluctuating trend. The fifth quintile has the highest income inequality and the most inequality in health expenditures because there are some households with high health expenditures in this group; while they are not rich in fact. The extended concentration index has been light fluctuation in the selected years. Increasing the extended concentration index represents the increasing inequalities in health expenditures, so an increase in this indicator is a sign of the worsening health situation in the country.

Despite of the improvements in some key health indices such as the rate of maternal mortality, the under five years mortality, life expectancy of women and men, the findings of this study show that the households' expenditure inequality increases in favor of the higher income groups, and on the other, the public policy in health has not been effective as expected. Moreover, the results of the study indicate that higher degree of inequality aversion parameter, the lower disparity between the average households' health expenditures and its average at the "perfect equality." This result shows that the capability of the individuals, and particularly the lower income groups, has been weakened.
\end{abstract}

Index Terms-health inequalities, health economics, inequality, health policy

\section{INTRODUCTION}

During the last two centuries, many changes have been made in lifestyle, community relations, and health issues leading to various social, environmental, and psychological problems [1]. The health domain system grew by increasing the popular awareness about the effect of developing factors (such as industrialization of society, road transportation, environmental damage, and trade globalization). Although, in addition to promoting health services and responding to

Published on May 29, 2019

Ali Maher. A/Professor, chancellor consultant, Department of Health Policy, school of management and medical education, Shahid Beheshti University of Medical Sciences, Tehran, IR Iran. Tel: +98-9121979704, (Email: dralimaher@gmail.com) people's expectations, the health systems need to provide lower prices of health services [2]. Therefore, these systems are responsible for protecting families against the financial costs of health care [3]. According to the defined scopes of the United Nations Millennium Declaration established and announced by the UN General Assembly, these duties are considered as developed recipes, including comprehensive goals to reduce poverty, hunger and improving the socioeconomic well-being of the people. In the meantime, some key issues in the health sector show the importance of this sector in developing a country. Among these goals one may refer to the reducing death rate of babies under one year old, reduction of child mortality under five years, improving the maternal health situation, struggling with AIDS and Malaria and other diseases, and stopping the spreading of such disease, etc. [4].

On the other hand, according to the United Nations Development Programs in 1990, the health index is one of the three key indicators of human development which refers to the role of the infrastructure in the development of countries. In the constitutional law of the Islamic Republic of Iran, the provision of the health has recognized as one of the fundamental rights, and the government is responsible for providing the necessary facilities of the health for citizens [5]. In fact, health is among the most important factors in human life, and it is an essential component in human empowerment [6]. Beginning the development programs in Iran, key indices of health such as life expectancy, mortality rates of children under one and five years and survival of women during pregnancy, from 1970 to the present has been improved. Some of these indices are represented as follow:

\section{A. Life expectancy}

According to statistics, life expectancy in Iran has changed from 49.5 years in 1960 to 51 years in 1980. It's concluded that before the 1979 revolution, life expectancy has grown only 1.5 years during 20 years. While from 1980 to 1988 during Iran- Iraq war, despite high population growth, life expectancy rose from 51.2 years to 61.6 years representing the social policies movement towards health supply in the aftermath of the 1979 revolution. From 1988 to 1997, life expectancy has reached to 69.5 years, in 2003 to 69.8 years and 2010 to 72 years. In recent years, life expectancy has improved to about 73 years. Obviously, the small changes in high levels of life expectancy are very costly [26].

Zahra Fazel (*Corresponding Author). Department of Economic, Alzahra University/ Tehran, IR Iran/ / Tehran, IR Iran. Tel: +98-9109658970/ (Email: z.fazel110@yahoo.com ) 
TABLE I: THE LIFE EXPECTANCY INDEX OF WOMEN AND MEN DURING THE IMPLEMENTATION YEARS OF DEVELOPMENT PROGRAMS IN IRAN

\begin{tabular}{|c|c|c|}
\hline Life expectancy & women & men \\
\hline $\begin{array}{c}\text { The average years of first development program } \\
\text { (1989-1993) }\end{array}$ & 66.78 & 63.22 \\
\hline $\begin{array}{l}\text { The average years of second development program } \\
\text { (1995-1999) }\end{array}$ & 69.66 & 68.46 \\
\hline $\begin{array}{l}\text { The average years of third development program } \\
(2000-2004)\end{array}$ & 72.1 & 69.74 \\
\hline $\begin{array}{l}\text { The average years of fourth development program } \\
\text { (2005-2009) }\end{array}$ & 74.38 & 71.12 \\
\hline $\begin{array}{l}\text { The average years of fifth development program } \\
\text { (2011-2015) }\end{array}$ & 76.17 & 73.75 \\
\hline
\end{tabular}

In spite of the growth of the national average indices, social achievements have not been distributed well geographically. The statistical center of Iran estimates the differences in life expectancy between Tehran as an improved region and other unimproved regions such as Sistan-Baluchestan about ten years. The differences between the lowest social classes of Sistan-Baluchestan Province with a more affluent population of Tehran is more than the number as mentioned above [27]. It is worth noting that the differences in life expectancy between poor blacks and rich white people are more than twenty years in America [7]. Considering the life expectancy of women and men in Iran and comparing with the world average and also the members of the Economic Cooperation and Development Organization OECD indicates the country's rank in the global arena. Figures 1 and two respectively show the comparison of the life expectancy of women and men in Iran and the world and OECD (according to the World Bank statistics).

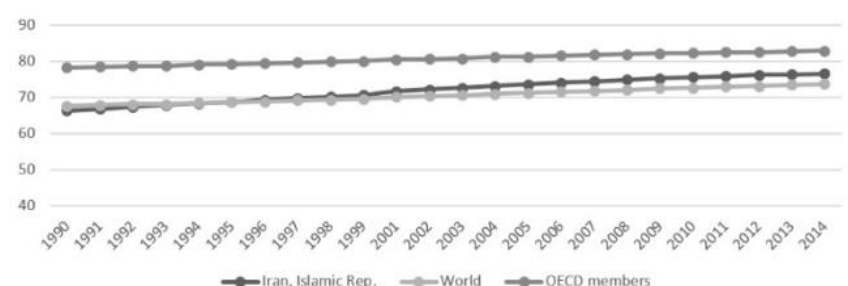

Figure1: comparison of the life expectancy of women in Iran, world and OECD

According to figure 1, the women's life expectancy until 1994 was below the global average; but after 1994, this index has had an ascending trend, and it's always higher than the global average as well. Comparing this index in Iran and the economically advanced countries (OECD) shows that the life expectancy of Iranian women has always been lower than OECD countries, although this difference has decreased in recent years.

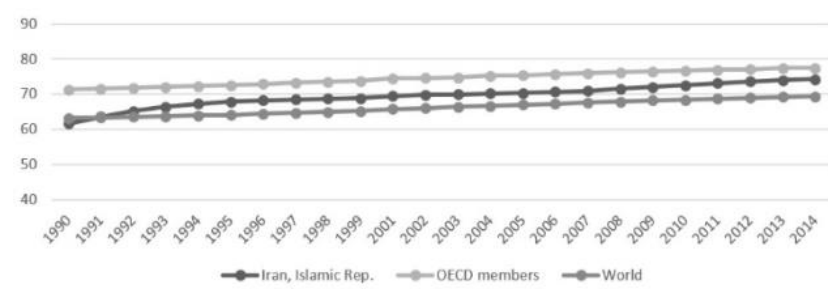
OECD

Figure2: comparison of the life expectancy of men in Iran, world and

Figure 2 shows that the life expectancy index for men in Iran has been higher than the global average since 1991 with an upward trend with less slope respect to the women's life expectancy. The difference in the life expectancy index between Iranian men with men of OECD countries is much lower than the life expectancy of Iranian women compared to the women of OECD countries; such that this difference has decreased greatly in recent years.

\section{B. The Under five year mortality}

The level of child mortality is considered as an indicator of global development. The international community has established numerous periodic goals to reduce the child mortality rate [8]. Declaration of Alma-Ata in 1978 was formed to reduce the child mortality to less than 50 deaths in per 1000 live births, by the strategy of "health for all until 2000" [9]. After that, since the world summit for children in 1990, there has been a great tendency to estimate the exact mortality rate of children under five [10]. Another international effort is targeting child mortality as the Fourth Millennium Development Goal. This goal is aimed to reduce the under-five-year child mortality to the level of two thirds from 1990 to 2015 [11].

\begin{tabular}{lc} 
TABLE II: UNDER FIVE MORTALITY RATE (PER 1000 LIVE BIRTHS) IN IRAN \\
\hline \multicolumn{1}{c}{ Index } & $\begin{array}{c}\text { Under Five } \\
\text { Mortality Rate }\end{array}$ \\
\hline $\begin{array}{c}\text { The average years of first development program } \\
(1989-1993)\end{array}$ & 54.86 \\
\hline $\begin{array}{c}\text { The average years of second development program } \\
\text { (1995-1999) }\end{array}$ & 41.06 \\
\hline $\begin{array}{c}\text { The average years of third development program } \\
\text { (2000-2004) }\end{array}$ & 30.9 \\
\hline $\begin{array}{c}\text { The average years of fourth development program } \\
\text { (2005-2009) } \\
\text { The average years of fifth development program } \\
\text { (2011-2015) }\end{array}$ & 22.86 \\
\hline
\end{tabular}

According to the United Nations children's fund statistics, in 2008 , the mortality rate of children under five years has been declining. This statistics represents a $28 \%$ reduction in the mortality rate of children's under five years, from 90 death (per 1000 live births) in 1990 to 65 death (per 1000 live births) in 2008. The new statistics provided by UNICEF show that during the past two decades, the mortality of children under five has declined continuously. The average of the reduction rate from 2000 to 2008 is equal to 2.3 percent, while it was 1.4 percent between 1990 to 2000 [12].

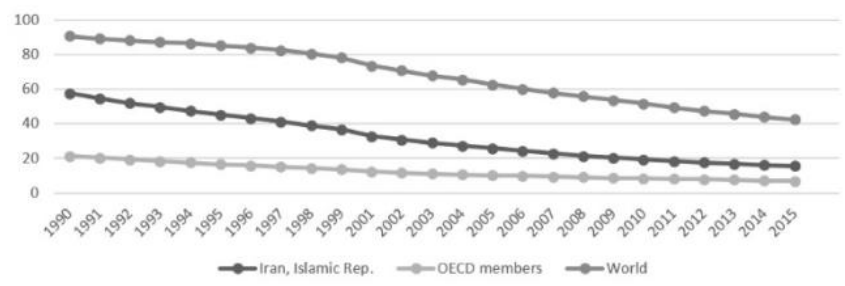

Figure 3. Comparison under five mortality rate in Iran, world and OECD

As figure 3 shows, according to the World Bank statistics, the under-five mortality rate in Iran has always been lower than the global average, and it's higher than the corresponding rate in OECD countries. The under-five mortality rate has been declining since 1990 .

\section{The rate of maternal mortality}

In this index, the rate of maternal mortality during pregnancy are discussed. According to the World Bank statistics, the maternal mortality rate was declining from 1990 
to 2014 .

TABLE III. THE MATERNAL MORTALITY (PER 100000 LIVE BIRTHS) IN IRAN

\begin{tabular}{cc}
\hline Index & $\begin{array}{c}\text { The Maternal } \\
\text { mortality rate }\end{array}$ \\
\hline $\begin{array}{c}\text { The average years of first development program } \\
(1989-1993)\end{array}$ & 104 \\
\hline $\begin{array}{c}\text { The average years of second development program } \\
(1995-1999)\end{array}$ & 39.6 \\
\hline $\begin{array}{c}\text { The average years of third development program } \\
(2000-2004)\end{array}$ & 29.2 \\
\hline $\begin{array}{c}\text { The average years of fourth development program } \\
(2005-2009) \\
\text { The average years of fifth development program } \\
(2011-2015)\end{array}$ & 25.75 \\
\hline \hline
\end{tabular}

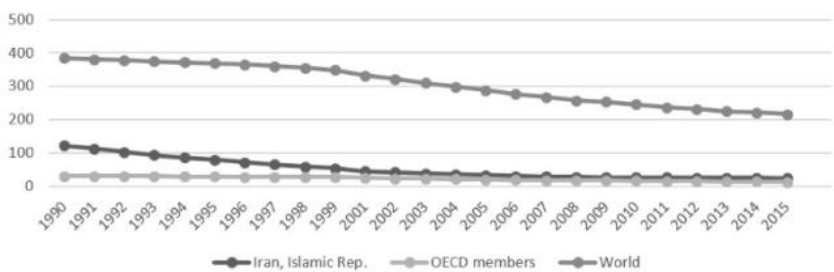

Figure 4. Comparison rates of maternal mortality in Iran, world and OECD

According to figure 4, similar to the Under Five Mortality Rate of children, the rate of maternal mortality in Iran has been lower than the global average, and the trend is clearly downward. Obviously, the rate of maternal mortality during pregnancy has been declining in Iran and OECD countries. This decline is sharper in Iran; such that the rate in Iran and OECD countries are very close in recent years.

The trend of indicators shows an improvement in the health situation in Iran. This improvement arises from various factors, which among them one may refer to the following: upgrading medical technologies in the health sector, increasing and improving drugs for A-contagious diseases, vaccination and improving mother's health care during pregnancy and childbirth. It is worth mentioning that although these factors are considered as key targets in improving the health of a country, improving health indicators for society will not be stable without the infrastructure of equitable distribution of income and financial resources of health. The lack of equity in health leads to questions about the health indicators of low-income groups; including whether the increase in life expectancy among the low- income has increased as much as highincome or not [13].

Diseases and health issues related to equality and social equity are the components of core concepts - inequalities in health care and access to health care related to social equity and health equality. Health equity is the product of broader social arrangement of social equity that includes other items, such as distributive equity, sufficient attention to the role of health in human life, and his freedom [14]. Equity in health should be evaluated from various aspects, including the ability to access appropriate health services. So, not only it consists of the distribution of health care services, but also it is including equity in processes that minimize discrimination in health care services [4]. In this way, the two key aspects in health sector arise: first, to achieve long and healthy life, according to the health sector and its promotion has utmost priority; because health is an important measure of human development and it is influenced by other social-economic benefits, such as appropriate training. Second, the establishment of a fair distribution system of services and fair participation in spending on health requires to the establishment of more comprehensive social-economic equity, such as equity in the distribution of income and wealth [13]. Since the inequalities in health affected the well-being of households and lead to various forms of social damage, this study aims to measure the inequalities in health costs and to examine the trend of changes in selected years.

In health studies in developing countries such as Iran, there always has been the lack of adequate statistical data [15]. Thus, broad and deep studies are very difficult in these countries, due to the statistical limitations. The result can be ambiguous, leading to incomplete policies and the resulting expensive trial and error approaches [13].

In the following, some of the studies in the field of inequality in the health sector are reviewed.

The fairness of health care financing sources checked by Kakwani index among OECD countries. Private financing system in OECD countries had a more unfair distribution of the financial burden [16].

The inequalities in health care considered by using of concentration index and its curve. The results show that the direct payments of health care costs among poor households are more than rich households. Also, inequality of pay-out of pocket depends on the amount of insurance coverage of people in different insurance plans. And the richer people have more possibility to access health care [17].

A method introduced to compare the health indicators of inequality in health and income based on short and long term's measures of health and income. They used a general health questionnaire (GHQ) and applied the time series. They showed that how the time series data linked to the crosssectional data of Gini coefficient and concentration index for pure health inequality (measured by the Gini coefficient) and health-related income inequality (measured by concentration index) [18].

Reference [19] shows the examination of the equity in financing health of Malaysia in 1998 and 1999. The main aim of this study was to evaluate health inequality. They used the household expenditure survey and analyzed them using STATA software. This study examined supplier of the financial resources of the household's health costs, including taxes, social insurance, and private insurance of health and pay-out of pocket for health costs. They also used kakwani index to evaluate the inequality. The results showed that kakwani index in financing costs of health was about 0.186 .

Reference [20] introduced the concentration index to measure the relative social-economic inequalities in health and health care. They compared the health financing system and transferred it in the Netherlands, United States, Italy, and the United Kingdom. They showed that in all these countries, 
there had been health inequalities and in England is more than others.

Low -income households paid about 40 percent of their meager income for their health care, which is 4.5 percent more compared with 9 percent of the households in top income's decile. Despite increasing coverage of the insurance organizations, and growth of supplemental insurance, still more than half of the costs of health care are paid out of pocket in all income groups [28].

Reference [24] shows the measurement of the inequalities in health costs in Iran. They calculated inequality in health costs in urban and rural areas by analyzing of household's survey microdata in 1989 and the early years of development programs of Iran. They used indices such as Gini coefficient, concentration index, kakwani index, and Atkinson index. The results show that the concentration index fluctuated in different regions of Iran. Kakwani index fluctuated in urban and rural areas and based on the Atkinson index; inequality was not improved in health costs.

Inequality of urban and rural areas of Iran was calculated for the years between 1997 and 2007 by using of household's expenditure data from the statistical center of Iran by using Lorenz curve and Kakwani index. Moradi divided the studied period to (1997-2001) and (2002-2007) and simulated data into two periods using a bootstrap technique. He studied the equity in health financing payment by creation of a pseudo statistical population. The results of this study show that equality in health care spending in urban households is less than rural households. A slight improvement was observed in rural areas. Kakwani index was negative in urban and rural areas. The participation ratio of the richest quartile to the poorest quartile in rural and urban areas in health care was respectively 8.79 and 8.01 as in [25].

The estimation of the inequality in household's health expenditure estimated in Iran and considered the breakdown of income's cohorts (two high cohorts, middle cohort, two bottom cohorts) by using the extended concentration index and health achievement index introduced by Wagstaff in 2002. The least inequality occurred in 2011; while the highest inequality varied between 1991 and 2007 depending on the value assigned to the inequality aversion parameter. Nevertheless, the trend of inequality in the studied period was generally increasing. The average of the concentration extended index and the health achievement index during the study period was 0.59 and 101884.1 , with standard deviation as 0.03 and 3231.56 , respectively [13].

All of these studies are similar in the field of health inequalities, emphasizing that the equity in health is one of the primary objectives of any country; so any negligence in providing the equity in health leads to unpleasant consequences on the development of the country. The major efforts of researchers are directed to show the inequality more accurate and correct by introducing different indices. In this study, highlighting the importance of the health sector in the future of the development of the country, and the necessity of imposing proper policies and infrastructure in this section, the concentration and extended concentration indices in elected years are examined.

\section{METHODOLOGY}

To investigate the inequalities in the financing of health spending during the implementation of the development programs in Iran, the "concentration index" and "extended concentration index" are examined. The household expenditure data is used as a substitute of the actual amount of household income, and the calculation domain is not limited to the whole country, but also being investigated for the expenditure quintiles of the Iranian household. Separation by quintiles provides a better understanding of the inequalities in different income groups. To this end, Iran's annual Household Survey data produced by Iran Statistic Center from 1984 to 2014 was used. And the calculations were done for beginning years of the implementation of development programs including 1989 , 1995, 2000, 2005, 2011, and 2014, and the effects of government policies and programs in these years were compared using soft wares EXCEL and STATA.

\section{A. Concentration index}

The concentration index is defined concerning the concentration curve as twice the area between the concentration curve and the line of equality (the 45-degree line). For the concentration curve with the $\mathrm{x}$-axis as the cumulative proportion of people and $y$-axis as the cumulative proportion of disease (people ranked by their income from the poorest to the richest, so that the starting point is related to the most disadvantaged person); if the graph is above the diagonal line, the inequality is in favor of high-income groups, and if the graph is below the diagonal line, inequality is in favor of the low-income groups. The concentration index varies between -1 and +1 . So in the case of full equality, the value of the index is zero, and by getting far from zero, the value of inequality increases. Positive index means inequality's concentration is in favor of high-income groups, and negative index means inequality's concentration is in favor of low-income groups [21]. The concentration index used in this study is calculated as follows:

$$
2 \delta_{r i} *\left(\frac{h_{i}}{\mu}\right)=\alpha+\beta_{r_{i}}+\varepsilon_{i}
$$

Where hi is the variable of health expenditure, $\mu$ is the average of health expenditure, $r_{i}=i / n$ is the fractional rank of the person $i_{\text {th }}$ in distribution of standard life, $i=1$ represents of the poorest person in the distribution and $\mathrm{i}=\mathrm{n}$ is attributed to the richest person, $\delta_{r_{i}}$ is the variance of the fractional rank, and the OLS of $\beta$ is an estimate of the concentration index. A concentration index is a useful tool for measuring inequalities in the health sector; however, it has some limitations. First, like the Gini coefficient, it has implicit in it a particular set of value judgments about aversion to inequality. But, the "extended" concentration index allows attitudes to inequality to be made explicit and to see how measure inequality changes as the attitude to inequality changes. The second drawback of the concentration indexand the generalization of it - is that it is just a measure of inequality. Although equity is an important goal of health policy, it is not the only one. It is not just health inequality that matters; the average level of health also matters. Policy makers are likely to be willing to trade one off against the other - a little more inequality might be considered 
acceptable if the average increases substantially. This points to a second extension of the concentration index (Wagstaff 2002): a general measure of health "achievement" that captures inequality in the distribution of health (or some other health sector variable) as well as it is mean [23].

\section{B. The extended concentration index}

The concentration index is written as follow:

$$
C(v)=-\frac{v}{n \cdot \mu} \sum_{i=1}^{n} h_{i}\left(1-R_{i}\right)^{(v-1)} \quad v>1
$$

In equation (2), $v$ is the inequality-aversion parameter, the weight attached to the $i_{\text {th }}$ person's health share, $h_{i} / n \mu$ is equal to $v\left(1-R_{i}\right)^{(v-1)}$. For $v=2$, the weight is the same as the regular concentration index; and $\mathrm{C}(2)$ is the standard concentration index. For $v=1$, everyone's health is weighted equally and so, the inequalities in health are not important for $\mathrm{C}(1)=0$; however, unequally health is distributed across the income distribution. As $v$ grows above 1, the weight attached to the health of very poor persons increases, and the weight attached to the health of the people who are above the 55th percentile decreases. For $v=6$, the weight attached to the health of the persons in the top two quintiles is virtually zero. When $v$ is grown to 8 , the weight attached to the health of those in the top half of the income distribution is virtually zero [21].

Alternatively, the extended concentration index is computed on microdata by means of a convenient regression. The appropriate convenient regression is given by:

$$
-\operatorname{vvar}\left[\left(1-R_{i}\right)^{(v-1)}\right] \cdot\left[\frac{y_{t}}{\mu}\right]=\alpha_{1}+\beta_{1} \cdot\left(1-R_{i}\right)^{(v-1)}+\mu_{t}
$$

Where $\beta_{1}$ is the extended concentration index [21].

\section{RESULTS}

In this section, the extended concentration index is calculated, and the inequalities in household income are investigated by using of Gini coefficient. The households' health expenditures in Iran disaggregated into expenditure quintiles of Iranian households. This disaggregation provides more accurate results of the distribution of health expenditure between different income groups. Therefore, considering the trend of indices provides the situation of inequality of health expenditure in Iran for selected years.

According to table IV, income inequality has almost descending trend during the selected years in the whole

\begin{tabular}{|c|c|c|c|c|c|c|}
\hline \multirow{2}{*}{$\begin{array}{l}\text { index } \\
\text { year }\end{array}$} & \multicolumn{6}{|c|}{ Gini coefficient } \\
\hline & Whole country & First quintile & Second quintile & Third quintile & Forth quintile & Fifth quintile \\
\hline 1989 & 0.433 & 0.226 & 0.163 & 0.150 & 0.150 & 0.344 \\
\hline 1995 & 0.447 & 0.211 & 0.157 & 0.150 & 0.155 & 0.345 \\
\hline 2000 & 0.435 & 0.211 & 0.154 & .0148 & 0.148 & 0.325 \\
\hline 2005 & 0.436 & 0.195 & 0.148 & 0.143 & 0.144 & 0.321 \\
\hline 2011 & 0.379 & 0.190 & 0.142 & 0.139 & 0.135 & 0.293 \\
\hline 2014 & 0.376 & 0.189 & 0.135 & 0.131 & 0.134 & 0.283 \\
\hline
\end{tabular}

TABLE IV. THE ESTIMATED INEQUALITY OF URBAN HOUSEHOLD'S INCOME

Source: findings of research

\begin{tabular}{|c|c|c|c|c|c|c|}
\hline index & \multicolumn{6}{|c|}{ Concentration index } \\
\hline year & Whole country & First quintile & Second quintile & Third quintile & Forth quintile & Fifth quintile \\
\hline 1989 & 0.449 & 0.213 & 0.134 & 0.094 & 0.164 & 0.282 \\
\hline 1995 & 0.5 & 0.231 & 0.187 & 0.168 & 0.214 & 0.376 \\
\hline 2000 & 0.51 & 0.254 & 0.153 & 0.17 & 0.142 & 0.454 \\
\hline 2005 & 0.54 & 0.201 & 0.114 & 0.161 & 0.186 & 0.452 \\
\hline 2011 & 0.433 & 0.168 & 0.114 & 0.093 & 0.105 & 0.251 \\
\hline 2014 & 0.454 & 0.184 & 0.089 & 0.101 & 0.106 & 0.262 \\
\hline
\end{tabular}

TABLE V. THE ESTIMATED INEQUALITY OF HEALTH EXPENDITURE OF URBAN HOUSEHOLD

Source: findings of research country and quintiles. The lowest level of income inequality in the whole country and quintiles is in 2014. Among quintiles, the fifth quintile has the highest income inequality. Table V shows the results of the concentration index in the whole country as well as quintiles. Both tables IV \& V show that the inequality of health expenditures are greater than income inequality in the whole country. Inequality of health expenditure shows the descending trend as well as income inequality. The highest inequality of health expenditures and income inequality occurred in the fifth quintile.

In the following, the trend of extended concentration index was examined during the selected years:

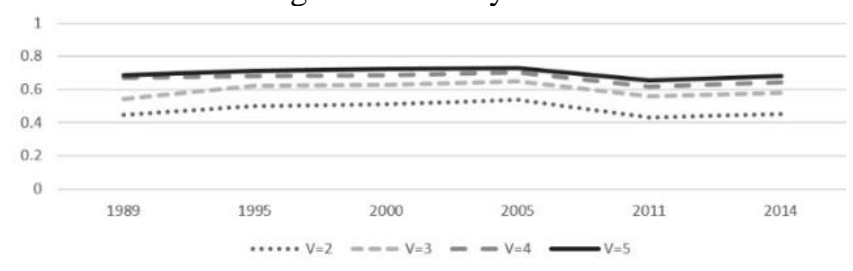

Figure 5. The trend of extended concentration index during selected years in whole country (urban region)

Figure 5 shows the trend of inequality in health expenditures by using of extended concentration index during the selected years. It is clear that by rising of the inequality aversion parameter $(v)$, the inequality increases from zero, which shows perfect quality. The trend of this index is light over the selected years. A considerable decrease was seen in the value of this index in 2011. For the case of $v=2$ (standard concentration index), the lowest inequality occurred in 1989 (at a rate of 0.449 ), and the highest inequality occurred in 2005 (at a rate of 0.540). With the rise of inequality aversion parameter, this amount has been increased for all years. For example, in $\mathrm{v}=5$, the lowest inequality is related to 2011 at a rate of 0.656 , and the highest amount is in 2005 at a rate of 0.731 . Therefore, the trend of inequalities is not quite similar to the different inequality aversion parameters. With increasing the aversion parameter of the inequality, due to the prevailing social-economic conditions and income inequalities, paying ability of people for access to health experiences undergoes different fluctuations. Positive index over the selected years clearly shows the existence of inequality in health expenditures in favor of high-income groups. In other words, the high-income groups have greater access to health services [13]. 


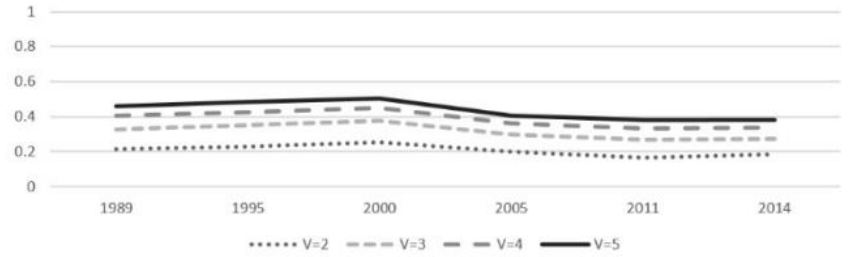

Figure 6 . The trend of extended concentration index during selected years in first quintile

According to figure 6, the trend of inequality in health expenditures is very light during the selected years, in the first quintile. In 2000, inequality of health expenditures was more than the other years for different aversion parameters. For $\mathrm{v}=2$, the highest inequality is related to 2000 at a rate of 0.254 , and the lowest inequality occurred in 2011 at a rate of 0.168 . Also for $\mathrm{v}=5$, the highest and the lowest inequality occurred in 2000 and 2014 respectively. In the first quintile with the rise of inequality aversion parameter, inequality in health expenditures increased as well as the whole country.

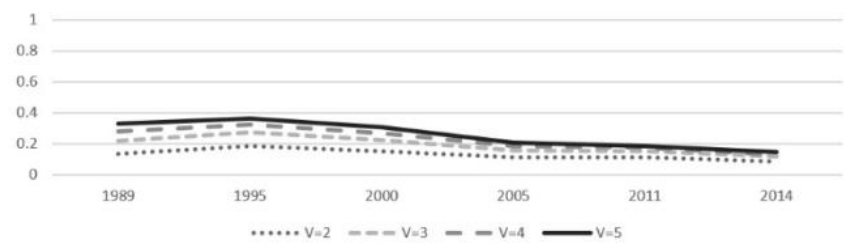

Figure 7. The trend of extended concentration index during selected years in second quintile

Figure 7 shows the trend of inequality in health expenditures in the second quintile. It is clear that inequality in health expenditure has a downward trend in selected years for different aversion parameter. And 2014 shows the lowest inequality and 1995 shows the highest rate of inequality. Inequality in the second quintile is lower than the inequality in the first quintile. It means that the households in the second quintile encountered with less inequality in health expenditures, and they have greater access to health services.

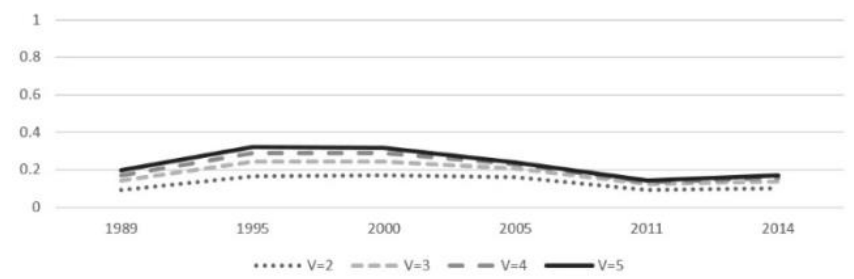

Figure 8 . The trend of extended concentration index during selected years in third quintile

Figure 8 shows that households in the third quintile encountered with less inequality compared to the first and second quintiles. The extended concentration index has a fluctuating trend. The lowest amount of inequality is related to 2011 for different aversion parameters. For $\mathrm{v}=2$, the highest inequality is related to 2000 at a rate of 0.170 ; and for $\mathrm{v}=5$, the highest inequality is related to 1995 at a rate of 0.323 .

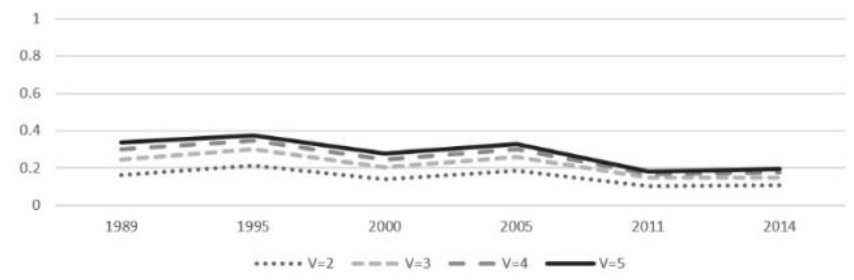

Figure 9. The trend of extended concentration index during selected years in forth quintile

Figure 9 shows the trend of extended concentration index in forth quintile. This index obviously fluctuates more severe compared with other quintiles. The highest inequality occurred in 1995, and the lowest occurred in 2014. For v $=2$, the lowest inequality is related to 2011 at a rate of 0.105 , and the highest is related to 1995 at a rate of 0.214 . Also for $v=5$, the highest the lowest inequality occurred in 1995 (at a rate of 0.377 ) and 2011 (at a rate of 0.181 ), respectively.

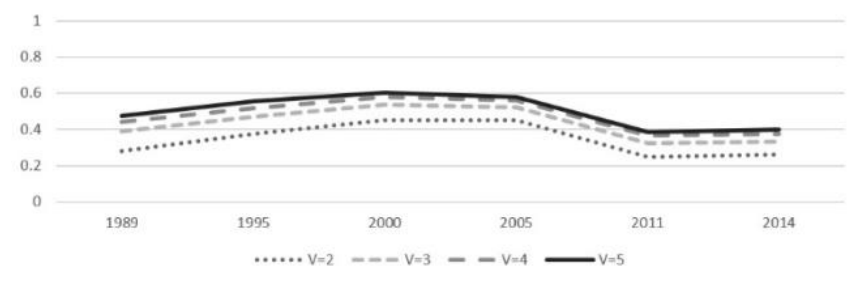

Figure 10. The trend of extended concentration index during selected years in fifth quintile

Figure 10 shows the trend of inequality in health expenditures for the fifth quintile. The changes were increased at first, followed by a downward trend after 2000 . Thus, the highest inequality occurred in 2000 , and the lowest one occurred in 2011.

As a result, households in the third quintile encountered with less inequality in health expenditures; and the second and fourth quintiles stand in the next ranks. Households in the fifth quintile are faced with the highest inequality with different aversion parameters. With increasing aversion parameter, inequality is increased in all quintiles. On the other hand, all the values are positive; which shows that inequality is in favor of high-income groups in all quintiles.

\section{DISCUSSION}

In this study, some of the main indicators of the health sector were examined; such as the rate of maternal mortality, the under five-year mortality, life expectancy of women and men. The trend of above-mentioned indices was better than the global average; however, the $t$, rent of these indicators were lower than OECD members, but this gap has decreased in recent years. An image of household's income inequality was presented by using of Gini coefficient. The trend of inequality in health expenditures of urban households was investigated in whole the country and five quintiles by using of concentration index and extended concentration index. To this end, Iran's annual Household Survey data produced by Iran Statistic Center was used for selected years. This study examined expenditures paid out of the pocket for health care of the house the old.

Checking the Gini coefficient for household's income reflects the reduction in the whole country and quintiles in selected years. The fifth quintile shows the highest income inequality.

The concentration index of health expenditure has always been positively representing that inequality in health expenditures are always in favor of high-income groups. The concentration index has an upward trend from 1989 to 2005, and after that, it has fluctuation. The fifth quintile has the highest income inequality and the most inequality in health expenditures. This group involves some households with high health expenditures which are not really rich, leading to increase of the inequality. This group of households may sell part of their underlying assets, and perhaps they have financed through borrowing to pay their health costs. Because 
of the high cost, they have been in the so-called wealthy groups of society. Although these calculations are in terms of per capital household expenditures, but because of the high proportion of treatment costs in the total expenditures, the percent of households have been in the high quintile.

Rising inequality has a more negative effect on health expenditures of low- income groups. Policies in the health sector can be directed to compensate for the inequalities of economic policies, or even acts in a discriminatory manner by increasing the effects of inequality [13].

The extended concentration index has light fluctuations in the selected years. Increasing the extended concentration index showed increasing inequalities in health expenditures, so the growth of this indicator is a sign of the worsening health situation in the country. All values obtained for this index has always been positive in whole country and quintiles. Therefore, it is a serious warning to the inadequate quality situation of the household's health expenditure. Increasing the positive value of index leads that high-income groups pay more health costs than low-income groups. This could be due to a high ability to pay in the high-income groups in access to health services. Increasing the negative value of index means that low -income groups are spending more health expenditures than high-income groups, and the concentration of health costs are in favor of low-income groups.

The results of this study correspond to Raghfar et al. (2013). So, it is concluded that there is inequality in health expenditures in Iran, and the policies to decreasing inequality in health expenditures did not work properly.

\section{CONCLUSION}

Despite the improvements in some key health indices mentioned in the first part of the study, it was focused on the inequalities of health expenditures by using of concentration index and extended concentration index to develop proper policy-making and equitable distribution of the health sector. The results showed that inequality in health expenditures had been rising trend until 2005, and then it has fluctuation. The positive values of this inequality showed that there is inequality in favor of high-income groups. In fact, according to the increasing inflation rate in Iran in recent years (fourth and fifth development programs), and manifold inflation in health sector consequently, low- income households face with more damage due to the rising cost of health goods and services. Because for low- income households, the share of foods, tobacco, and housing costs are allocated a significant part of the household's budget. So, the rising prices of goods and services in the health sector lead to a reduction in the purchasing power of households. Also, the pressure of rising costs leads that low-income families spend more of their budgets to their health care.

The results of quintiles show the unequal status in household expenditures. Fluctuations in high-income groups were more than low-income groups. So, the results show that there is inequality in the distribution of income and health expenditures in Iran; and there are gaps among different expenditure's groups.

According to the above items and the situation of mentioned and calculated indices in Iran, we can conclude that increasing of people's access to health services, increasing of the health level and fair distribution of health level among people, required to correct program in using of public resources. So, health category should be as a priority for planners of country, and the purely economic and costly look at health and treatment sector should be reclaimed; then with a new approach to health category, planning should be done to achieve the goals of development plans in Iran.

Undoubtedly, by focusing on overall health policies, prioritize prevention to treatment, promotion of quality and quantity of services for vulnerable groups of people especially for decades of low income, modification of tariffs, cooperation between governmental and private organizations involved in health sector, planning based on the real economic power of the government and avoiding of infliction of unbearable expenses on it, we can see not only the promotion of health indices but also providing satisfaction of people in society.

\section{REFERENCES}

[1] B. Salehi, H. Solhi, A. R. Fotovat, D. Motamedi, SH. Moradi, and S. Ebrahimi, "The comparison of the psychiatric disorders between opium addicts' families referring to opium withdrawal clinics and nonaddicts' families referring to blood transmission centers." Arak University of Medical Sciences Journal, vol.15 (3), pp. 32-8[Article in Persian]. 2012.

[2] M. Yousefi, A. Assari Arani, B. Sahabi, and A. Kazemnejad, "Direct and indirect costs of household health expenditure," Hospital, Vol. 12(4), pp. 51-61[Article in Persian]. 2014.

[3] The world health report 2013: Research for universal health coverage. Geneva: World Health Organization, pp. 5-21.

[4] Human Development Report 2003, UNDP, New York: Oxford University Press.

[5] Planning and Budget Organization, First Human Development National Report of Islamic Republic of Iran. Planning and Budget Organization, Iran. Tehran, pp. 123-12. 1999.

[6] A. Sen, Why Health Equity? In: S. Anand, F. Peter, A. sen, eds, Public Health Ethics and Equity, 1th ed, Oxford: Oxford University Press, 2004, pp.21-35.

[7] M.R. Vaez-Mahdavi, Z. Vaez-Mahdavi, M.M. Araei, "The Impact of Social Policies on Human Development Following the 1979 Islamic Revolution in Iran," International Journal of Healthcare, Insurance and Equity, Vol. 1, No. 2. 2013.

[8] T. Moultrie, R. Dorrington, A. Hill, K. Hill, I. Timaeus, B. Zaba, “Tools for demographic estimation," Paris: International Union for the Scientific Study of Population. 2013.

[9] Development of indicators for monitoring progress towards health for all by the year 2000, World Health Organization. Geneva. 1981.

[10] C.J.L. Murray, T. Laakso, K. Shibuya, K. Hill, A.D. Lopez. Can we achieve Millennium Development Goal 4? New analysis of country trends and forecasts of under-5 mortality to 2015, Lancet 2007, vol. 370(9592), pp.1040-1054

[11] Panel UHL. Millennium development goals, 2013, (Report).

[12] Available: https://www.unicef.org/iran/fa/, [in Persian].

[13] H. Raghfar, S. Gholami, "Households' Health Expenditure Inequality in Iran: 1984-2011," Hakim Research Journal, vol. 16(4), pp. 302- 316 [Article in Persian]. 2014.

[14] A. Case, D. Lubotsky, C. Paxson, Economic Status and Health in Childhood: The origins of gradient, American Economic Review 2002, vol. 92(5), pp. 1308-1334.

[15] H. Graham, Introduction: The Challenge of Health Inequalities. In: Graham Hilary. Understanding Health Inequalities. 1th ed, New York: Mc Grow Hill Press, pp. 1-21, 2010.

[16] D. Wagstaff, "Equity in the Finance of Health Care: Some International Comparisons," Journal of Health Economics, vol. 11, pp.361-387. 1992.

[17] M. Makinen, H. Waters, M. Rauch, N. Almagambetova, R. Bitran, L. Gilson, et al. "Inequalities in health care use and expenditure: empirical data from eight developing countries and countries in transition," World Health Organization, vol. 78, pp. 55-65. 2000. 
[18] A.M. Jones, A.L. Nicolas, "Measurement and explanation of socioeconomic inequality in health with longitudinal data," Health Econ. 13, pp. 1015-1030, 2004.

[19] P.Y. Chai, D.K. Whynes, T.H. Sach. "Equity in health care financing: The case of Malaysia," Bio Med Central, International Journal for Equity in Health 2008, vol. 7(15), pp. 1-14.

[20] A. Wagstaff, E. van Doorslaer, P. Paci, "Equity in the finance and delivery of health care: Some tentative cross-country comparisons," Oxford Review of Economic Policy 1989, vol. 5, pp. 89-112.

[21] A. Wagstaff, "Inequality Aversion, Health Inequalities and Health Achievement," Journal of Health Economics 2002, vol. 21, pp. $627-$ 641.

[22] N.C. Kakwani, A. Wagstaff, E. Van Doorslaer, "Socioeconomic inequalities in health: measurement, computation and statistical inference," Journal of Econometrics 1997, vol. 77, pp. 87-103.

[23] O. O'Donnell, E. Doorslaer, A. Wagstaff, M. Lindelow, Analyzing Health Equity Using Household Survey Data, The World Bank Institute.

[24] H. Raghfar, N. Zargari, K. Sangari Mohazzab, "Measuring Inequality in Households' Health Care Expenditures in Iran," Hakim Research Journal 2013, vol. 16(2), pp. 89-97[Article in Persian].

[25] A. Moradi. Equity of health care financing: an application to Iran, [Cited 2011 Sep. 18]. Available: http://mpra.ub.unimuenchen.de/33489/.

[26] V. Mahdavi, M.R. Farshad Momeni, H. Raghfar, F. Heidary, "inequalities in the mirror of research," Publishers of Shahed University, [Article in Persian]. 2009.

[27] S.A.L. Marandi, "Social determinants of health," Comprehensive public health book, Chapter 13, article 31, [Article in Persian]. 2006.

[28] SH. Semnani, AA. Keshtkar, "Estimate of fairness of health care cost in the coverage area of population research base of Gorgan," Journal of medical sciences of Gorgan university, issue 12, autumn and winter, pp. 9-53 [Article in Persian], 2003.

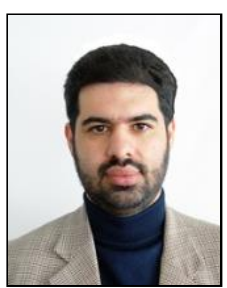

\section{Ali Maher}

Shiraz, Iran. May 1972

B.A; M.A. \& Ph.D. in health care management in Aazad univeristy of Iran \& Post Doctoral Program in Health financing in Malaysia (2005).

Some of his books and articles are published by different journals:

1) Pensions in the Middle East and North Africa: time for change, 2018; social security research institute, Tehran, Iran. ISBN: 978-964-6923-48-5

2) Self - assessment system: business results. 2018; Shahid Sadoughi university of medical and health services in Yazd province of Iran. , ISBN: 964-5661-36-6

3) Survey of Different Approaches to Health System Financing in the Selected Countries during the Period 1998-2004 and Introducing New Financing Mechanisms for Iran. Research in Economics 06/2018; 8(1).

4) Ali Maher, Arezoo Dehghani, "Government Hospitals in the Health Transformation Plan: Reducing the Patient's Franchise by Paying for the Difference, Reducing the Price of Drugs and Equipment, Adhering to Referral System and Using Family Physician and Laboratory Network, Supporting Extending the Basic Health Insurance Coverage and Accumulation of Insurances, Looking at the Achievements and Challenges Ahead." "...

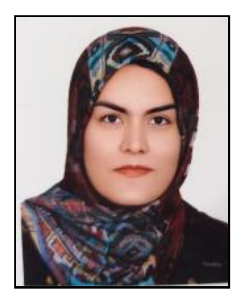

\section{Zahra Fazel}

Qom, Iran, January 1990.

Bachelor of applied mathematics, Qom university, Qom, Iran (2012).

Masters of economic development and

planning, Alzahra university of Tehran, Tehran, Iran (2017).

She worked on health economics major for her dissertation and both papers. The first paper which is called "Analysis Equity in

Financing of Household's Health in Development Programs of Iran" is published in Hakim journal in Iran in 2018, [Article in Persian]. 